\title{
STERLE WATER INJECTION VERSUS DICLOFENAC SODIUM AS A POST CAESARIAN SECTION PAIN RELIEVER
}

\author{
Ahmed El Sayed Elbohoty (MD.)*, Mohamed Atef Behery (MD.)**, Ahmed Mohammed Hashad (MD.)*, \\ Marwa Hamad Yousef (MD.)* \\ *Department of Obstetrics and Gynecology, faculty of medicine, Ain shams University, Cairo, Egypt \\ **The International Islamic Center for Population Studies and Researches, ART Unit, Al-Azhar University, \\ Cairo, Egypt.
}

\section{ABSTRACT}

Background: Childbirth is an important experience in a woman life, so high quality postoperative analgesia is important because the mother has to recover from major intra-abdominal surgery for proper caring of her newborn baby. Analgesic medications are either pharmacological or non-pharmacological methods. Pharmacological methods commonly used for postoperative pain relief after caesarean section either opioids or non-opioids and non-pharmacological methods include many techniques that reduce painful stimuli, as used for management of low back pain in labor. Sterile water injection is a simple and inexpensive way to provide a medication - free option to women who want to either avoid or delay use of opioid or non-opioid analgesia

Methodology: 94 women who had attended the maternity hospital at Ain Shams University hospital from June 2013 to the end of December 2014 and indicated for Caesarian section, were randomized into 2 groups: group I $(\mathrm{n}=47)$ included women who received post Caesarian section subcutaneous injection of $0.5 \mathrm{ml}$ sterile water, and group II $(\mathrm{n}=47)$ received intramuscular $3 \mathrm{ml}$ of $75 \mathrm{mg}$ Diclofenac sodium. Assessment of pain score in total subjects for need additional analgesia and assessment of maternal side effects was conducted in both groups.

Results: there are statistically significant difference between both groups as regard onset of pain relief $(23 \pm 9.9$ and $16 \pm 6.4)$ in group 1 and 2 respectively with P-value $(<0.001)$. Also 13 cases in group $\boldsymbol{I}$ needed additional analgesia while no cases needed in group II (28\% and $0 \%)$ respectively with P-value $<0.001$.As regard appearance of side effects 5 cases showed side effects(flushing and stinging pain) in group 1 and no recorded side effects in group $2(11 \%$ and $0 \%)$ respectively with $\mathrm{P}$-value $=0.022$.

Conclusion: sterile Water was found to be safe, simple and efficient method of pain relief after caesarean section and free from major negative side effects which associated with other methods. In spite of these advantages, non-steroidal analgesics seems to has the priority in view of potency, rapid analgesia and the less side effects.

Key words: Sterile water, Diclofenac Sodium, Ceasarian section, Pain

Corresponding Author: Ahmed El Sayed Elbohoty

Received: $\quad 13$ September 2015

E-mail: behery133@hotmail.com

Accepted: $\quad 30$ September 2015

\section{INTRODUCTION}

O ver the last two decades the number of caesarean sections being performed has increased ${ }^{[1]}$.Childbirth is an important experience in a woman life, so high quality postoperative analgesia is important because the new mother has to recover from major intra-abdominal surgery, also caring for her newborn baby ${ }^{[2,3]}$. The American College of Obstetricians and Gynecologists (ACOG) and American Society of Anesthesiologist issued a joint statement indicating that a women's request for pain relief is sufficient medical indication for pain relief ${ }^{[4]}$.

Analgesic medication either pharmacological or non-pharmacological methods, pharmacological methods commonly used for postoperative pain relief after caesarean section either opioids or non-opioids and nonpharmacological methods include many techniques that reduce painful stimuli, as used for management of low back pain in labor ${ }^{[5,6]}$ Centrally acting opioid drugs such as, morphine or its derivatives are usually used to achieve postoperative pain relief, but it associated with side effects such as, itching, nausea, vomiting, sedation and respiratory depression ${ }^{[7]}$. Diclofenac sodium, a potent prostaglandin synthesis inhibitor, it is one of non-Steroidal Anti-Inflammatory analgesics that is particularly effective against the visceral pain that arises from uterine incision following caesarean section ${ }^{[8]}$. They have a well-documented opioid-sparing effect, such as peptic ulceration, gastritis, renal 
impairment and in addition, these drugs are excreted in mother milk "small amount" ${ }^{[9,10]}$.

An idea post-caesarean analgesic regiment would be one that was cost-effective, simple, have high quality pain relief but have low incidence of side effects and complications, also it would not interfere with the maternal care of newborn or with the establishment of breast feeding and would be minimal drug transfer into breast milk ${ }^{[11,12]}$.Sterile water injection is a simple and inexpensive way to provide a medication - free option to women who want to either avoid or delay use of opioid or non-opioid analgesia. Subcutaneous injection technique in presacral region is less painful than intracutaneoas technique and is shown to be more tolerable for patients ${ }^{[13]}$.Cutaneous sterile water injection was showed to be effective in reducing low back pain in laboring women without side effects on fetus or mother ${ }^{[14]}$.

Injection of sterile water stimulates nociceptors and has action resembles acupuncture $^{[15]}$.Counterirritation, the phenomenon of one painful stimulus reducing pain caused by a second noxious stimulus, may explain the pain reducing effect of sterile water injection and a cupuncture ${ }^{[16]}$. Diffuse noxious inhibitory controls (DNICS) is the inhibition of multireceptive neurons in dorsal horn of spinal cord, so pain is reduced in body regions remote from those at which stimuli are presented ${ }^{[17]}$.Many studies have concluded that injection of sterile water in presecral region was effective in relief of low back pain during labor ${ }^{[\mathbf{1 8}]}$.Intracutaneous or subcutaneous injection of sterile water is rapidly gaining popularity as a method of pain relief in labour and it is therefore essential that it is properly evaluated. Adequate analgesia in labour is important to women worldwide. Sterile water injection is inexpensive, requires basic equipment, and appears to have few side effects. It is purported to work for labour pain ${ }^{[19]}$. So we did this study to show the analgesic effect of subcutaneous injection of sterile water on Egyptian women after caesarean section, one of important Obstetrics operations.
Aim of the work: To evaluate the pain relieve efficacy of subcutaneous sterile water injection in pre-sacral region in comparison to intramuscular diclofenac sodium injection during the early post- caesarean section delivery.

Methodology: 94 women, who admitted at Ain Shams University Hospital for caesarean section in the period from June 2013 to the end of December 2014, were approached on admission and estimate the indication of caesarean section, invited to participate in the study voluntarily after verbal explanation of the procedure with their verbal consent. The patient will be divided into two groups, group I: (47 Patients) received post-operative sterile water and group $\boldsymbol{I I}:(47$ Patients) received post-operative diclofenac sodium. Both groups fulfilled the selection criteria as follows; age is 18-40 years, booked for caesarean section, of any gestational age according to indication of caesarean section, the procedure should be under general anesthesia without use of narcotics during anesthesia, the patients selected were not allergic to NSAIDS, no history of bronchial asthma, no diabetes, no hypertension, no liver diseases and no bleeding diathesis. Following admission, all patients were undergoing detailed medical and obstetrics history, complete clinical examination and each patient had a case record form (CRF) in which the following data were recorded. The investigators were delivering the study treatment only to patients included according to inclusion criteria described. The treatment provided by main investigators and stored in independent premises from usual medicine held by authorized people. The study medications were handed to be administrated for patients under supervision (dose by dose). The unused treatment - for any reason would be given back to investigator. After caesarean section women who seek analgesia divided into two groups; group I: received four subcutaneous injections of single dose sterile water $0.5 \mathrm{ml}$ (Pfizer Egypt Pharmaceutical Company) in the lumbosacral region (Michaelis' rhomboid) at the positions shown in (Figure1, 2) after 
caesarean sections when patients needing analgesia and group II: received single dose intramuscular injection of diclofenac sodium (Novartis Pharmaceutical Company, Switzerland) $3 \mathrm{ml}$ of $75 \mathrm{mg}$ using $3 \mathrm{~cm}$ syringe in gluteal region.

Administration techniques of sterile water:
The anatomic points were palpated as follows: The woman lying on her lateral side in bed, the skin was cleaned with alcohol and the posterior superior iliac spines palpated by feeling the bony prominences just lateral to the sacrum and below the iliac crest (Figure. 1, 2)

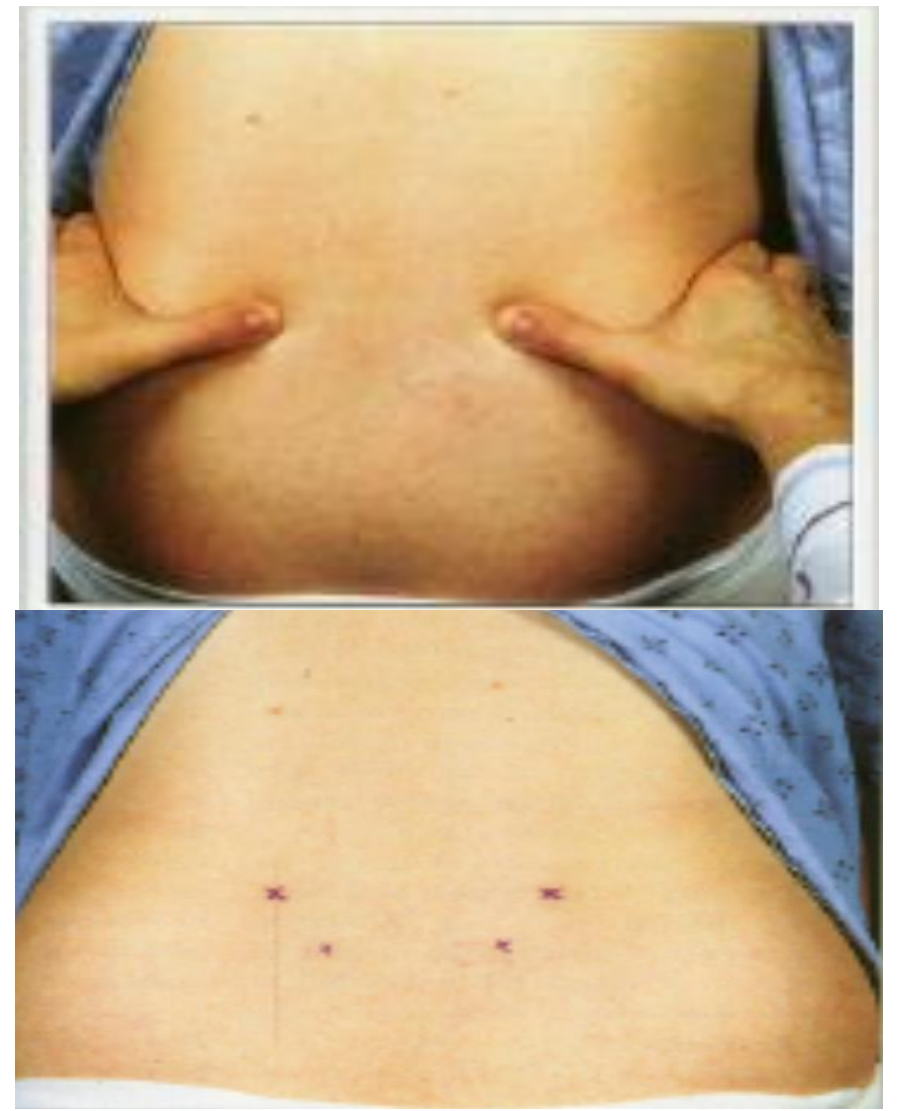

Figure-(1, 2): The anatomical pointes of sterile water injection

The insulin needle with $2 \mathrm{ml}$ sterile water placed subcutaneous in four locations each $0.5 \mathrm{ml}$ on the lower back, two over each posterior superior iliac spine (PSIS) and two $3 \mathrm{~cm}$ below and $1 \mathrm{~cm}$ medial to the PSIS

\section{Pain assessment}

Visual analogue scale (VAS): Assessment of pain relief was performed by the observers in written form for visual analogue scale (VAS) before injection, at $0.5 \mathrm{~h}$ after, $1 \mathrm{~h}, 2 \mathrm{~h}, 3 \mathrm{~h}$ and 4h (Figure 3) ${ }^{[20]}$.Also the patient was asked to tell about the degree of pain by marking the appropriate point on the line with the help of Verbal Numerical Rating Scale from(VNRS) $(0-100)$ (Figure 4) ${ }^{[21]}$ before injection and at $0.5 \mathrm{~h}, 1 \mathrm{~h}, 2 \mathrm{~h}, 3 \mathrm{~h}$ and $4 \mathrm{~h}$ after giving the injection. 


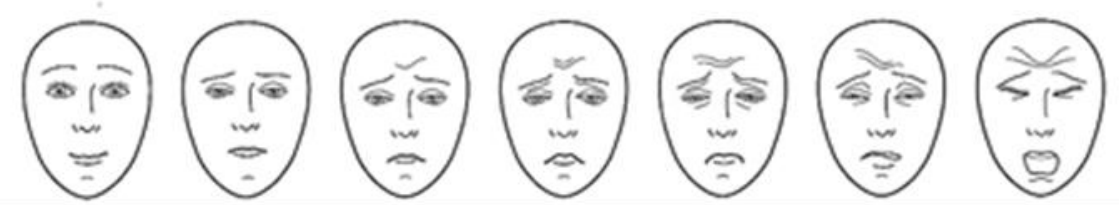

Figure-3- The Faces Pain Scale for Assessment of the Severity of Pain. We ask the patient to mark on the line the pain she feels

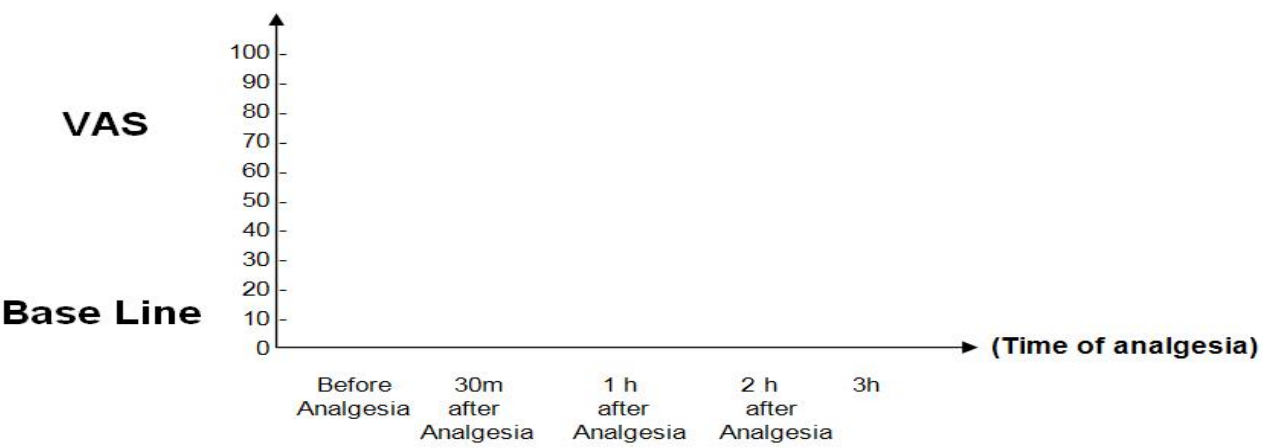

No pain $\begin{array}{lll}8 & 9 & 10\end{array}$ The most

Figure-4: VAS chart.

In this scale, patient was asked about: (1) The onset of pain relief after analgesia. (2) The degree of pain relief after each hour within the first 4 hours. (3) The required additional doses of analgesia (4) The local side effects (namely burning pain and flushing after injection of sterile water).

This was done for all patients (sterile water and diclofenac sodium groups)

Statistical analysis: The collected data were coded, tabulated, and statistically analyzed using SPSS program (Statistical Package for Social Sciences) software version 17.0.Descriptive statistics were done for numerical parametric data as mean \pm SD (standard deviation) and minimum \& maximum of the range, while they were done for categorical data as number and percentage. Inferential analyses were done for quantitative variables using independent t-test in cases of two independent groups with parametric data and paired t-test in cases of two dependent groups with parametric data.Kolmogrove Semirinove test was used as a test for normality. Inferential analyses were done for qualitative data using Chi square test for independent variables. The level of significance was taken at $\mathrm{P}$ value $<0.050$ is significant, otherwise is non-significant. The $p$-value is a statistical measure for the probability that the results observed in a study could have occurred by chance .P values $(\mathrm{P}) \leq$ 0.05 were considered statistically significant. The sample size was estimated depending on the alpha error $(5 \%)$, the power of the study $(80 \%)$ and at least $30 \%$ effect size difference between both types of treatment in any direction(two tails study) and was calculated using Epi-info 7 software program for Microsoft Windows (CDC ,Atlanta, USA). Randomization w

\section{RESULTS}

This randomized study (clinical trial) was conducted to compare subcutaneous sterile water injection in the pre-sacral region with intramuscular diclofenac Sodium for relief of pain after caesarean section. All subjects had caesarean section under general anesthesia and seeking analgesia, 94 women were randomized into 2 groups: group I $(n=47)$ included women who received subcutaneous injection of $0.5 \mathrm{ml}$ Sterile water, and group II $(\mathrm{n}=47)$ received intramuscular $3 \mathrm{ml}$ of $75 \mathrm{mg}$ diclofenac Sodium. 
Table (1): General Characteristics for both groups.

\begin{tabular}{|c|c|c|c|c|}
\hline & $\begin{array}{l}\text { Sterile water } \\
\text { group } \\
(\mathrm{N}=47)\end{array}$ & $\begin{array}{l}\begin{array}{l}\text { Diclofenac } \\
\text { group }\end{array} \\
(\mathrm{N}=47)\end{array}$ & $\mathrm{p}$ & Sig. \\
\hline Age (years) $($ Mean \pm SD) & $28.0 \pm 7.1$ & $27.4 \pm 5.0$ & 0.640 & NS \\
\hline $\begin{array}{l}\text { Gestational age }(\mathrm{GA}), \\
\text { (weeks) Mean } \pm \text { SD }\end{array}$ & $38.0 \pm 2.2$ & $37.7 \pm 2.6$ & 0.552 & NS \\
\hline Weight $(\mathrm{Kg})$ Mean \pm SD & $68.0 \pm 14.0$ & $70.6 \pm 11.9$ & 0.325 & $\mathrm{NS}$ \\
\hline Height $(\mathrm{m}).($ Mean \pm SD & $1.6 \pm 0.0$ & $1.6 \pm 0.0$ & 0.847 & $\mathrm{NS}$ \\
\hline $\mathrm{BMI}\left(\mathrm{Kg} / \mathrm{m}^{2}\right)$ & $26.6 \pm 4.4$ & $27.7 \pm 4.2$ & 0.221 & $\mathrm{NS}$ \\
\hline $\begin{array}{l}\text { Previous Deliveries , Mean } \\
\pm \text { SD }\end{array}$ & $1.9 \pm 2.0$ & $1.7 \pm 1.6$ & 0.691 & NS \\
\hline $\begin{array}{l}\text { Parity (Frequency \%) } \\
\text { Primigravida } \\
\text { Multigravida }\end{array}$ & $\begin{array}{l}11(23.4 \%) \\
36(76.6 \%) \\
\end{array}$ & $\begin{array}{l}12(25.5 \%) \\
35(74.5 \%) \\
\end{array}$ & 0.810 & NS \\
\hline $\begin{array}{l}\text { Previous Caesarean section } \\
\text { (frequency \%) } \\
\text { 1ry CS }\end{array}$ & $25(53.2 \%)$ & $26(55.3 \%)$ & & \\
\hline Repeat CS & $22(46.8 \%)$ & $21(44.7 \%)$ & 0.963 & NS \\
\hline
\end{tabular}

NS = non-significant

Table (2): Comparison between both groups as regard difference of VAS (the initial, at $30 \mathrm{~min}, 1 \mathrm{~h}$, 2 hrs, 3hrs.and 4 hrs.)

\begin{tabular}{lllll}
\hline Using100ml VAS & $\begin{array}{l}\text { Sterile } \\
\text { Water(n=47) }\end{array}$ & $\begin{array}{l}\text { Diclofenac } \\
(\mathrm{n}=47)\end{array}$ & $\mathrm{p}$ & \multirow{2}{*}{ Sig. } \\
\hline Initial & Mean $\pm \mathrm{SD}$ & Mean $\pm \mathrm{SD}$ & & \\
\hline After 30min & $82.9 \pm 8.2$ & $84.6 \pm 9.0$ & 0.324 & $\mathrm{NS}$ \\
\hline After 1 hour & $71.1 \pm 9.3$ & $64.6 \pm 10.3$ & 0.002 & $\mathrm{~S}$ \\
\hline After 2 hours & $60.3 \pm 12.5$ & $41.3 \pm 13.1$ & $<0.001$ & $\mathrm{~S}$ \\
\hline After 3 hours & $52.9 \pm 12.7$ & $25.2 \pm 10.8$ & $<0.001$ & $\mathrm{~S}$ \\
\hline After 4 hours & $43.3 \pm 16.9$ & $11.0 \pm 8.7$ & $<0.001$ & $\mathrm{~S}$ \\
\hline
\end{tabular}

$\mathrm{S}=$ Significant; $\mathbf{N S}=$ Non significant

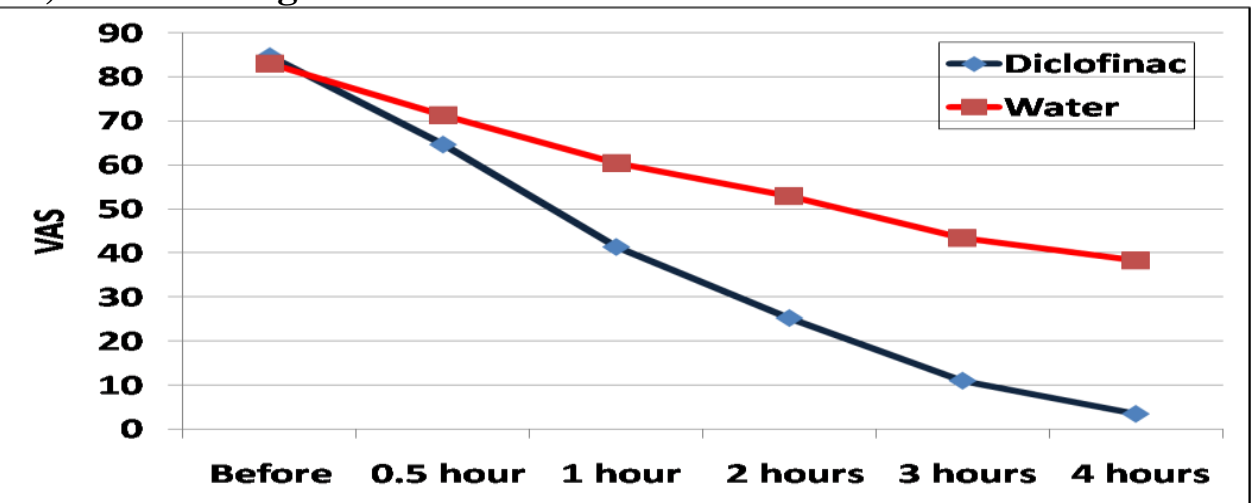

Figure (5): Comparison between sterile water and diclofenac in reduction of pain score 
Table (3): Comparison between sterile water and diclofenac groups as regard the onset of pain relief, side effects and additional analgesia

\begin{tabular}{|c|c|c|c|c|}
\hline & $\begin{array}{l}\text { Sterile } \\
\text { Water(n=47) }\end{array}$ & $\begin{array}{l}\text { Diclofenac } \\
(\mathrm{n}=47)\end{array}$ & \multirow[t]{2}{*}{$\mathrm{p}$} & \multirow[t]{2}{*}{ Sig. } \\
\hline & Mean \pm SD & Mean \pm SD & & \\
\hline $\begin{array}{l}\text { Onset of pain relief } \\
\text { (minutes) }\end{array}$ & $23.0 \pm 9.9$ & $16.4 \pm 6.4$ & $<0.001$ & S \\
\hline \multicolumn{2}{|c|}{ Additional analgesia } & & \multirow{3}{*}{$<0.001$} & \multirow{3}{*}{$\mathrm{S}$} \\
\hline Yes & $13(27.7 \%)$ & $0(0.0 \%)$ & & \\
\hline No & $34(72.3 \%)$ & $47(100 \%)$ & & \\
\hline \multicolumn{5}{|l|}{ Side effects } \\
\hline Yes & $5(10.6 \%)$ & $0(0.0 \%)$ & \multirow[t]{2}{*}{0.022} & \multirow[t]{2}{*}{$\mathrm{S}$} \\
\hline No & $42(89.4 \%)$ & $47(100 \%)$ & & \\
\hline
\end{tabular}

$\mathrm{S}=$ Significant; Data were presented as Mean \pm SD and $\mathrm{n}(\%)$

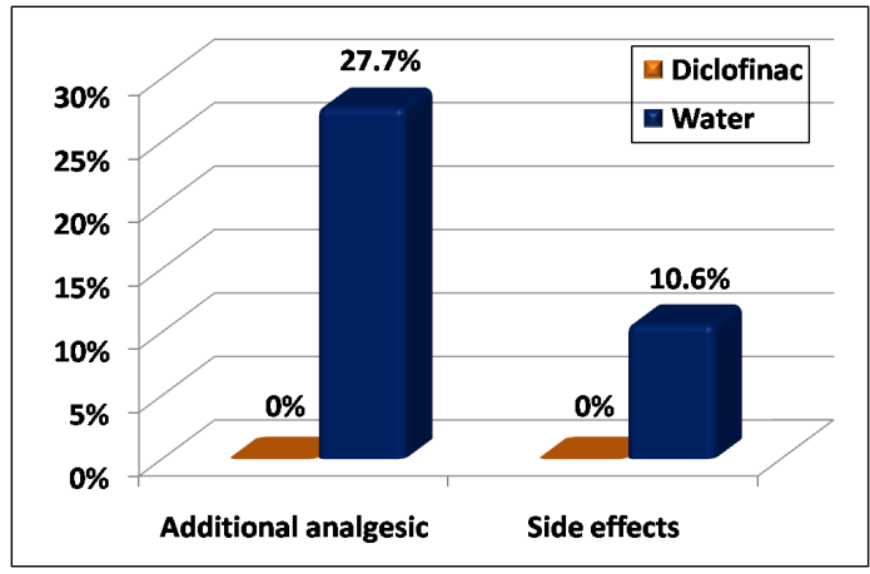

Figure (6): Comparison between Sterile Water and Diclofenac groups as regards to prognosis.

\section{DISCUSSION}

In response to the need of effective post caesarean pain management this prospective randomized comparative study was designed to compare the analgesic efficacy of subcutaneous sterile water injection as a nonpharmacological method to diclofenac sodium as a traditional NSAIDS.This was regarding the pain relief effects within the first 4 hours after 1ry or repeat CS done under general anesthesia, showed no statistical difference between both groups $(\mathrm{p}>0.05)$ as regard general data and obstetrics history, this seems to be due to proper randomization so both groups were well cross matched. Concerning the onset of pain relief after administration of sterile water (mean $=23.0 \mathrm{~min})$ versus diclofenac (mean=16.4min) showed rapid onset of pain relief for diclofenac than sterile water with rapid reduction of pain score using
VAS throughout the study in first 4 hours post caesarean section for diclofenac group, it may be due to anti prostaglandin effects of diclofenac on uterine cramps which is a source of postpartum pain ${ }^{[22]}$,while sterile water depends on the gate control theory and/or stimulation of endogenous opioid system $^{[23,24]}$.For sterile water results as the analgesic effect after caesarean section, it was near to previous studies done to control pain in laboring women and by using VAS in present study showed there was reduction of pain score after injection by $30 \mathrm{~min}$ (mean=71.1) and this agree with Martensson and Wallin; $1999^{[25]}$ also Trolle et al.,1991 ${ }^{[26]}$,after 1 hour the pain was reduced $($ mean $=60.3) \quad$ which agree with Wiruchpongsanon, 2006 ${ }^{[27]}$. and after 2 hours, pain continue to reduce (mean $=52.9$ ) that agree also with Wiruchpongsanon, 
200,but disagree with Martensson et al., $\mathbf{2 0 0 0}^{[28]}$, who said that after $90 \mathrm{~min}$ the pain score elevated and analgesic effect fade out and using 4hours for assessment of pain in present study disagree with Pralhad Kushtagi et al.,2009 ${ }^{[29]}$, who used $45 \mathrm{~min}$ only for pain assessment, but using sterile water pain assessment more than 1 hour agree with Wiurchpongsanon,2006 and Lena Martensson et al.,2008 ${ }^{[30]}$.

In comparison of the present study to other studies in needing the rescuer drugs after sterile water administration showed that, 13 of 47 women $(27.7 \%)$ in sterile water group complained of unrelieved pain within different times in early 4 hours postoperatively and were given further analgesia in form of Tramadol and NSAIDS but other previous collected data not assessed the need of rescuer drugs except Brooke, 2009 ${ }^{[31]}$, when repeated injection of sterile water every 2 hours showed reduction of pain score but the effect of repeated injections not evaluated in this study, it may be due to the pain pathway of sterile water.From included 5 (10.6\%) from 47 women in this study shown burning pain for few minutes and flushing after sterile water injection, it may be due to sterile water is hyposmolar and its injection probably irritate the nerves leading to brief pain initially then followed by analgesia resembles acupuncture which agree with Wright and Brorsson, $\mathbf{1 9 9 5}^{[32]}$, when compared sterile water and saline for relieving pain in myofascial pain syndrome found that, the saline injection was painless than sterile water injection and also this was agree with many researchers as Ader et al., 1990 and Martensson et al., 2000, but the flushing after the injection not discussed in previous studies and we need further studies to know the cause of flushing The using of subcutaneous route in four locations in lumbosacral regions in administration of sterile water was shown to be less painful and more tolerable than the intracutaneous injection which agrees with Martensson et al, $1995^{[33]}$ and also Martensson et al., 2000, but not agree with Bahsadri et al., 2006 when used one injection in most painful point in the sacrum.

For Diclofenac sodium as analgesic effect in early 4hours post caesarean section, shown scientifically adequate pain control, this agree with previous studies as Bush et al., 1992; ${ }^{\text {;34] }}$ Bourlert, 2005, ${ }^{[35]}$, when used single dose diclofenac intramuscular route in the first 12 hours post caesarean section showed dramatically reduction in VAS, for example VAS at 1 hour (mean $=4.71 \mathrm{~min}$ ) at 2 hours (mean $=3.65 \mathrm{~min}$ ) and at 6 hours (mean $=3.32 \mathrm{~min})$ in comparison with diclofenac in the present study at 1hour (mean $=41.3 \mathrm{~min}$ ), at 2 hours $($ mean $=25.2 \mathrm{~min}$ ) and at 4hours $($ mean $=3.5 \mathrm{~min})$ with serially decreased VAS. In contrast to this study, diclofenac showed its safety in reducing the requirement of rescuer drug in the first $4 \mathrm{~h}$ following caesarean section which 47 (100\%) women in the diclofenac group did not require additional analgesia throughout the study and this agree with prospective randomized controlled trials done by Olofsson et al., 2000 and Bourlert, 2005, it may be due to the plasma clearance of diclofenac takes about 4 to5 hours after intramuscular injection in healthy volunteers (Riess et al.,1978) ${ }^{[36]}$.

Other studies compared diclofenac with other analgesic drugs post caesarean section also provided its efficacy and safety in controlling pain which demonstrated that diclofenac reduce opioid requirement for pain relief after caesarean section (Hodsman et al., 1987) ${ }^{[37]}$ and it was similar to the results of study by Siddik et al., 2001 ${ }^{[38]}$ which shown that the combination of diclofenac and paracetamol reduced morphine requirements compared to diclofenac alone after caesarean section.In addition other operations rather than caesarean section shown efficacy of diclofenac in relieving pain, such as hysterectomy and perineal repair (Carlborg et al., 1987) ${ }^{[39]}$.Also after coronary artery bypass grafting (Fayaz et al., 2004) ${ }^{[40]}$.

This study not agrees with other reported results with different rout of administration, where a single dose of $100 \mathrm{ml}$ rectal diclofenac after caesarean section gave no pain relief (Dennis et al., 1995) ${ }^{[41]}$. 
In accordance with our expectation and the data in the literatures about the side effects observed during the study, we showed that no side effects recorded for diclofenac group throughout the study especially, abnormal bleeding or postpartum hemorrhage in early 4 hours post caesarean section despite the expectation of more uterine bleeding with diclofenac sodium due to its adverse effect on

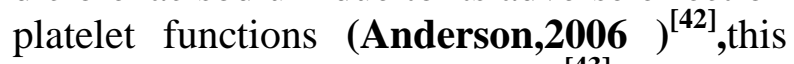
was agree with, Sia et al., 1997; ${ }^{[43]}$ Al-Waili, $\mathbf{2 0 0 1}^{[4]}$, and also with Rahmanpoor et al., $\mathbf{2 0 0 7}^{[\mathbf{4 5}]}$ who investigated that VAS for pain was significantly lower in diclofenac group compared to the pethidine group with more side effects for pethidine as nausea, vomiting, itching and abdominal distention. Intramuscular administration of diclofenac sodium was more common method used and reliable to patients whom agree with many researchers as, Al-Waili, 2001; O' Hanlon et al., $1996^{[46]}$, and disagrees with Lim et al 2001 $^{[47]}$ :Rashid and Jaruidi, $2000^{[48]}$;Ambrose, 2001 ${ }^{[49]}$ and Sia et al., 1997 who used diclofenac suppository and also Rorarius et al., $\mathbf{1 9 8 5}^{[\mathbf{5 0 ]}}$;Huang et al., 2002 $^{[51]}$ who used diclofenac by intravenous infusion.Visual analogue scale (VAS) as pain assessment in the present study, showed highly validity and reliability in pain quantification and was the measuring tool used by all studies for sterile water except Bahsadri et al., 2006 who used facing rating scale.

\section{CONCLUSION}

sterile Water was found to be safe, simple and efficient method of pain relief after caesarean section and free from major negative side effects which are associated with other methods. In spite of these advantages, non-steroidal analgesics seem to have the priority in view of potency, rapid analgesia and less side effects.

Acknowledgment: Many thanks to all anesthesia staff (doctors and technicians) at Ain Shams Maternity Hospital, without their efforts, this study could not be finished.

\section{REFERRENCES}

(1)Villar J, Valladares E, Wojdyla D, Zavaleta N, Carroli G, Velazco A: Caesarean delivery rates and pregnancy outcomes: the 2005 WHO global survey on maternal and perinatal health in Latin America. Lancet 2006; 367:18191829.

(2)Goodman P; Mackey C, Tavakoli :Factors related to childbirth satisfaction J Adv Nurs 2004;46212-219.

(3) World Health Organization: Pregnancy, childbirth, postpartum and newborn care a guide for essential practice, 2nd edition. Geneva: World Health Orgnization,2006; D89.

(4) American College of Obstetricians and Gynecologists: Committee ACOG. Opinion number 269 analgesia and cesarean delivery rates Obestet Gynacol 2000; 99:369-70.

(5) Pellegrini JE: Intrathecal opioid for the control of pain experienced during labor and in the post-cesarean section period.CRNA1998; 9:99-105.

(6) Simkin, $\mathbf{P}$ and $\mathbf{O}^{\prime}$ Hara M: Non pharmacological relief of pain during labor: systematic reviews of five methods. Am J Obstet Gynecol 2002; 186:5131

(7) Raffaeli W, Marconi G, Fanelli G, Taddei S, Borghi GB, Casati A: Opioid-related sideeffects after intrathecal morphin: a prospective, randomized, double-blind dose-response study. Eur J Anaesthesiol 2006; 23:605-610.

(8) Dahl V, Hagen IE, Sveen AM, Norseng H, Koss KS, Steen T: High-dose diclofenac for postoperative analgesia after elective caesarean section in regional anesthesia Int $\mathrm{J}$ Obstet Anesth 2004; 11:91-94.

(9) Olofsson CI, Legeby MH, Nygard EB, Ostman KM: Diclofenac in the treatment of pain after caesarean section. An opioid-saving strategy.Eur J Obest Gynecol Reprod Biol 2000; 88:143-146.

(10) Hale TW, Mc donald R, Boger J: Transfer of celecxib into human milk J Hum Lact 2004; 20:397-403.

(11) Yost NP, Bloom SL, Sible, Lo JY, Mcintire DD, Leveno KJ: A hospital-Sponsored quality impro-vement study of pain management after cesarean section. Am J Obstet Gynecol; 190: 1341-1346 demised controlled trial. Ann Surg;2004, 235: 333-337.

(12) Lavand'homme P: post caesarean: effective strategies and association with chronic pain. Curr Opin Anaesthesiol 2006; 19:244-238.

(13) Martensson L, Ader L, Wallin G: sterile water papules against labor pain. (A simple, safe, effective method) Lakaratidningen 1995; 92:2395-2396. (In Swedish) 
(14) Bahasadri S, Ahmadi-Abhari S, DehghaniNik M, Habibi GR.: Subcutaneous sterile water injection for labour pain: a randomised controlled trial. Aust N Z J Obstet Gynaecol.2006; 46:102-106.

(15) Ader L, Hansson B, Wallin G: Parturition pain treated by intracutaneous injections of sterile water.1990; 41:133-138.

(16) Melzack R: Prolonged relief of pain by brief, intense transcutaneous somatic stimulation .Pain 1975; 1:357-373.

(17) Le Bars D, Dickenson AH, Besson JM: Diffuse noxious inhibitory controls (DNIC). Effects on dorsal horn convergent neurons in the rat .Pain 1979; 6:283-304.

(18) Hutton, EK, Kasperink, M, Rutten M: Sterile water injection for labour pain: a systematic review and meta-analysis of randomized controlled trials.BJOG 2009; 116:1158.

(19) Derry S,Straube S,Moore RA,Hancock H,Collins SL(2012): Intracutaneous or subcutaneous sterile water injection compared with blinded controls for pain management in labour. Cochrane Database Syst Rev. Jan 2012; 18.

(20)Wong D,Hockenberry-Eaton M,Shwartz P,:Wongs essentials of pediatric Nursing ed.6,st.louis,p;2001:1301.

(21) Warden V, Hurley AC, Volicer L: Development and psychometric evaluation of the pain assessment in advanced dementia (PAINAD) scale. Journal of the American Medical Directors Association 2003; 4:9-15.

(22) Metz SA: Anti-inflammatory agents as inhibitors of prostaglandin synthesis in man. Med Clin North Am1981; 65:713-757.

(23) Melzack R and Wall PD: Pain mechanisms: a new theory. Science 1965; 150:971-979

(24) Andersson SA and Holmgrene E: An acupuncture analgesia and mechanism of pain Am J Chin 1975;3: 311-334

(25) Martensson $\mathbf{L}$ and Wallin G: Labour pain treated with cutaneous injections of sterile water: a randomised controlled trial. $\mathrm{Br} \mathrm{J}$ Obstet Gynaecol.1999; 106:633-637

(26) Trolle B, Moller M, Kronborg H, Thomsen S (1999): Effect of sterile water blocks on low back labor pain. Am J Obstet Gynecol.; 164(5 Pt 1):1277-1281.

(27) Wiruchpongsanon P (2006): Relief of low back labor pain by using intracutaneous injections of sterile water: a randomized clinical trial. J Med Assoc Thai.; 89: 571-576.
(28) Martensson L, Nyberg K, Wallin G (2000): Intracutaneous versus subcutaneous injections of sterile water for labour analgesia: a comparison of perceived pain during administration. $\mathrm{Br} \mathrm{J}$ Obstet Gynaecol.; 107:1248-1251.

29) Pralhad, Kushtaghi, Brasanvhalli, Thimmegouda, Bhanu (2009): Acta Obstetricia et Gynecologica,, 1_3, iFirst article

(30) Martensson L, Nyberg K, Wallin G: Intracutaneous versus subcutaneous injections of sterile water for labour analgesia: a comparison of perceived pain during administration. Br J Obstet Gynaecol.2008; 107:1248-1251.

(31) Brooks K: Sterile water injection for pain relief and gate control theory J Fam Pract 2009; 43:657-27

(32) Wright D, Paterson C, Scott N: Five year follow-up of patients undergoing laparoscopic or open groin hernia repair; 2002

(33)Martensson L, Ader L, Wallin G: sterile water papules against labor pain. (A simple, safe, effective method) Lakaratidningen1995: 92:2395-2396. (In Swedish)

(34) Bush DJ, LyonsG, MacDonald R: Diclofenac for analgesia after caesarean section .Anaesthesia1992; 47:1075-7.

(35) Bourlert A: Diclofenac intramuscular single dose to decrease pain in postoperative caesarean section: a double blind randomized controlled trial.J Med Assoc Thai 2005; 88:159.

(36) Riess W, Sallman A, Schmid K, Schweizer A, Sulc M, Theobald W, Wagner J: Pharmacokinetics and metabolism of the antiinflammatory agents Voltaren Scandanavian Journal of Rheumatology1978;7(Suppl.22):17

(37) Hodsman NBA, Burns J, Blyth A, Kenny GNC, Mcardle CS, Rotman H: The morphine sparing effects of diclofenac sodium following abdominal surgery. Anaesthesia 1987; 1005-1008.

(38) Siddik SM, Aouad MT Jalbout Ml, Rizk LB, Karnar GH, Baraka AS: Diclofenac and/or propacetamol for postoperative pain management after cesarean delivery in patients receiving patient controlled analgesia morphine Reg Anesth pain Med 2001;26:310315.

(39) Carlborg L, Lindoff C, Hellman A: Diclofenac versus pethidin in the treatment of pain after hysterectomy .Eur J Anaesthesiol 1987; 4:241-247. 
(40) Fayaz MK, Abel RJ, Pugh SC, Hall JE, Djaiani G,Mecklenburgh JS: Opioid sparing effects of diclofenac and paracetamol lead to improved outcomes after cardiac surgery .J Cardiothorac Vasc Anesth 2004;18:742-7.

(41) Dennis AR, Lesson-Payne CG, Hobbs GJ: Analgesia after caesarean section .The use of rectal diclofenac as an adjunct to spinal morphine .Anaesthesia 1995; 50:297-9

(42) Anderson M: Diclofenac and post-partum hemorrhage. Int J Obstet Anesth 2006; 15:341342.

(43) Sia AT, Thomas E, Chong JL, Loo CC: Combination of suppository diclofenac and intravenous morphine infusion in postcaesarean section pain relief a step towards balanced analgesia Singapore Med J 1997;38:68-70

(44) Al Wailli NS: Efficacy and safety of repeated postoperative administration of diclofenac sodium in the treatment of post caesarean section pain: a double-blinded study. Arch Med Res 2001; 32:148-154.

(45) Rahmanpoor H, Hosseini SN, Mousavinasab SN, Todayon P, Karimi F: Comparison of diclofenac with pethidine on the pain after caesarean section. International Journal of Pharmacology2007; 3:201-203.

(46) O'Hanlon JJ, Beers, H, Huss BK, Milligan KR: A comparison of the effect of intramuscular diclofenac, ketorolac or piroxicam on postoperative pain following laparoscopy .Eur J Anaesthesiol; 13:404407.(47) Lime MS, Van Duyn EB, Van Der GY (2003): Recurrences after conventional anterior and laparoscopic inguinal hernia repair: a randomized comparison. Ann Surg1996; 237: 136-141.

(48) Rashid M and Jaruidi HM: The use of rectal diclofenac for post caesarean analgesia .Saudi Med J 2000; 21:145-149.

(49) Ambrose FP: A retrospective study of the effect of post-operative indomethacin rectal suppositories on the need for narcotic analgesia in patients who had a caesarean delivery while they were under regional anesthesia. Am J Obest Gynecol 2001; 184:1544-1547; discussion 1547-1548

(50) Rorarius M, Miralles J, Baer GA, Palomaki E: Diclofenac versus indomethacin given as intravenous infusions: thir effect on haemodynamics and bleeding time and side effects in healthy subjects .Ann CDlin Res 1985;17:306-9.

(51) Huang YC, Tsai SK, Huang CH, Wang MH, Lin PL, Chen LK Lin CJ, Sun WZ: Intravenous tenoxicame reduces uterine cramps after caesarean delivery .Can J Anaeth 2002;49:384-387. 